\section{Estudo \\ cobebate}

em Testão

Plamejamento
Revista Estudo \& Debate, Lajeado, v. 24, n. 2, 2017. ISSN 1983-036X

DOI: http://dx.doi.org/10.22410/issn.1983-036X.v24i2a2017.1332

\title{
ORDENAMENTO TERRITORIAL EM FOCO: DISCUTINDO O PROGRAMA ACESSO À TERRA URBANIZADA
}

\author{
Daniela de Freitas Lima ${ }^{1}$, Almir Mariano de Sousa Junior ${ }^{2}$, \\ Manoel Mariano Neto da Silva ${ }^{3}$, William Vieira Gomes ${ }^{4}$
}

\begin{abstract}
Resumo: O ordenamento territorial é um dos fatores fundamentais para que as cidades evoluam de maneira equilibrada, permitindo que o crescimento seja sinônimo de progresso para todas as classes sociais. Associado ao ordenamento está a Regularizaçáo Fundiária de Interesse Social Urbana que visa a garantir o direito jurídico sobre o imóvel ocupado de forma pacífica por famílias de baixa renda. Nesse sentido, um agente colaborador para a potencialização da legalização de áreas irregulares é o Programa Acesso à Terra Urbanizada, que atua no Semiárido do Nordeste do Brasil com açóes de Regularização Fundiária de Interesse Social Urbana. O objetivo deste artigo é discutir a metodologia para efetivação de regularização de áreas adotadas pelo Programa Acesso à Terra Urbanizada. Para a elaboração deste trabalho, realizou-se o acompanhamento dos procedimentos executados pelo referido Programa, desde a concepção para a titulação da maior área objeto de intervençáo. Verificou-se que as contribuiçóes do Programa superam a atribuição de um título que assegure a posse de moradias para comunidades, pois suas atividades multidisciplinares envolvem discentes e docentes, incentivando a pesquisa e extensão, além de contemplarem estudos que podem ser julgados como subsídios ao ordenamento territorial, uma vez que descrevem com detalhes as características de áreas em foco, possibilitando a adoção de medidas de melhoria pelo poder público.
\end{abstract}

Palavras-chave: Ordenamento territorial. Regularização fundiária. Áreas de interesse social.

1 Graduanda em Engenharia Civil pela Universidade Federal Rural do Semi-Árido (UFERSA). E-mail: danielafreitas12@hotmal.com;

2 Doutor em Ciência e Engenharia de Petróleo. Professor da Universidade Federal Rural do Semi-Árido (UFERSA). E-mail: almir.mariano@ufersa.edu.br;

3 Graduando em Engenharia Ambiental e Sanitária pela Universidade Federal Rural do Semi-Árido (UFERSA). E-mail: marianop.paiva2@gmail.com;

4 Graduando em Engenharia Civil pela Universidade Federal Rural do Semi-Árido (UFERSA). E-mail: willvcarius@hotmail.com. 


\title{
TERRITORIAL ORDINATION IN FOCUS: DISCUSSING THE PROGRAMA ACESSO À TERRA URBANIZADA
}

\begin{abstract}
Spatial planning is one of the fundamental factors that cities grow evenly, allowing the growth is synonymous with progress for all social classes. Associated with the spatial planning is the land property regularization of Urban Social interest which aims to guarantee the legal right on the property occupied peacefully by low-income families. In this sense, an agent for the potentiation of the legalization of irregular areas is the Programa Acesso à Terra Urbanizada in the Semi-arid Northeast of Brazil with actions of agrarian regularization of Urban Social interest. The purpose of this article is to discuss the methodology for implementation of regularisation adopted by the Programa Acesso à Terra Urbanizada. For the preparation of this work, the monitoring of the procedures performed by this programme, from design to the titration of the largest object of intervention. It was found that the contributions of the program outweigh the assignment of a title to ensure the ownership of houses in communities, because their multidisciplinary activities involve students and teachers, by encouraging research and extension, in addition to contemplate studies that can be judged as grants to regional planning, once describing in detail the characteristics of areas in focus, enabling the adoption of measures by the Government.
\end{abstract}

Keywords: Regional planning. Land regularization. Areas of social interest.

\section{INTRODUÇÃO}

As cidades, de modo geral, são desafiadas pela irregularidade fundiária urbana, que pode ser tida como aspecto decorrente do processo constitutivo das cidades, especificamente notado por meio do crescimento acelerado e desordenado ocasionado pelo êxodo rural acentuado, a exemplo do Brasil, mais expressivamente a partir da década de 1960.

Para o Ministério das Cidades (2014), aproximadamente 18 milhóes de domicílios urbanos brasileiros são irregulares, o que corresponde a $31,7 \%$ do total. O Nordeste, regiáo em que está instaurado o objeto de estudo deste trabalho, concentra 33\% desse quantitativo.

Apesar de o problema do desordenamento urbano não ter sido prevenido, é possível buscar remediá-lo, tendo como uma das práticas para esta ação, o fomento da Regularização Fundiária Urbana, especialmente aquela voltada para as classes sociais menos favorecidas, em que se enquadra a Regularização Fundiária de Interesse Social. Esse tipo de regularização é pautado na Lei 11.977/2009, que trata do Programa Minha Casa, Minha Vida, marco federal que reflete um avanço na ênfase à melhoria do espaço para as pessoas de baixa renda.

Outro grande marco jurídico no combate à irregularidade fundiária foi a elaboração da Medida Provisória No 759, de 22 de dezembro de 2016, que dispóe sobre a regularizaçáo fundiária rural e urbana, sobre a liquidação dos critérios exigidos aos assentamentos da Reforma Agrária e sobre a regularização fundiária no âmbito da Amazônia Legal. Dessa maneira, simplifica a legitimação de posse, os processos de regularização de áreas e imóveis da União, regulamenta a legitimação fundiária e cria o direito real de laje.

Nesse sentido, cita-se como ente colaborativo na redução da irregularidade fundiária o Programa Acesso à Terra Urbanizada, que se concretiza na parceria entre a Universidade Federal Rural do Semi-Árido (UFERSA), do Rio Grande do Norte, e o Ministério das Cidades, na perspectiva de ampliar o direito à cidade em assentamentos de interesse social, por intermédio da promoçáo de Regularizaçáo Fundiária de Interesse Social Urbana. 
Assim, este artigo objetiva debater os procedimentos metodológicos de execução do Programa Acesso à Terra Urbanizada, discorrendo sobre as etapas inerentes ao processo desenvolvido através dele, desde a sua concepção para a titulação da maior área de intervenção. Destaca-se, neste estudo, o assentamento Parati, localizado no município de Assu/RN. Para tanto, realizou-se o acompanhamento dos procedimentos executados através do referido Programa no período de janeiro de 2015 a dezembro de 2016.

Ressalta-se que a Medida Provisória No 759, de 22 de dezembro de 2016 resultou em modificaçôes na Lei 11.977/2009, entretanto a abordagem adotada neste estudo utilizou como base os princípios a Lei 11.977/2009 anteriores à sua alteração, já que as atividades acompanhadas para a redação deste artigo foram executadas em data que antecede a publicação desta Medida Provisória.

\section{MATERIAIS E MÉTODOS}

Esta pesquisa tem abordagem qualitativa, uma vez que contextualiza as etapas das açóes de Regularização Fundiária de Interesse Social Urbana através do Programa Acesso à Terra Urbanizada, e classifica-se como descritiva exploratória, já que discute a realidade por meio da análise de dados coletados em campo.

Fez-se necessário acompanhar e participar diretamente de todas as atividades realizadas pelo Programa, que são: articulaçáo e diagnóstico para a escolha dos assentamentos urbanos junto ao poder público municipal e ao cartório; sensibilização e mobilização das lideranças comunitárias e da população; levantamentos planialtimétricos e produção cartográfica; regularização da base imobiliária; cadastro social e assinatura dos títulos; aberturas das matrículas nos cartórios; e, a titulação das moradias presentes nos assentamentos beneficiados. A partir desse acompanhamento, foi possível realizar registros fotográficos e acessar as informaçóes para elaborar este estudo.

\section{IRREGULARIDADE FUNDIÁRIA E (DES)ORDENAMENTO URBANO}

A irregularidade fundiária urbana é um fator presente nas diversas cidades, independentemente do tamanho e desenvolvimento, e que causa instabilidade para as famílias localizadas em áreas sem a devida legalização, pois impede a inserção de seu lote no programa citadino do município. O Ministério das Cidades (2009) ressalta no livro "Regularização Fundiária Urbana no Brasil" que a legalidade e a ilegalidade do território brasileira estão associadas à sua formação, o que acentua as desigualdades entre ricos e pobres nas cidades brasileiras.

Confirmando a segregação existente por meio do padrão legal versus ilegal, Fernandes (2011) expressa que nos assentamentos informais, que comumente ocorrem em terrenos públicos ou ambientalmente vulneráveis, geralmente há a falta de serviços públicos essenciais, como saneamento, e que o padrão de desenvolvimento é irregular. Explica que sem alternativas devido ao baixo poder aquisitivo, as classes menos favorecidas são expulsas para as áreas mais periféricas das cidades, muitas vezes sem segurança jurídica; instaladas em Áreas de Preservação Permanente, o que acentua a impossibilidade de alocação; ou suscetíveis a desastres, como desabamentos e alagamentos. Nesse sentido, Maricato (2003) 
menciona que a ausência de alternativas habitacionais urbanas, seja por intermédio do mercado privado, seja pela deficiência de políticas públicas sociais, é o propulsor da ocupação ilegal e predatória da terra.

Nessa perspectiva, pode-se afirmar que a irregularidade fundiária é um elemento do desordenamento urbano, pois causa danos para ambos os segmentos da sociedade: população acometida e governo. Concordando com essa afirmação, Fernandes (2011) expõe que a informalidade das habitaçóes gera custos muito altos para os residentes e governos locais. Para os moradores, cita-se: a insegurança da posse, a falta de serviços públicos, a discriminação por terceiros, perigos ambientais e para a saúde e desigualdade de direitos civis. Para os governos, estão a realização de programas de melhoria, quando realizados, e custos indiretos decorrentes da informalidade, como problemas de saúde pública, violência e outros de cunho social.

O próprio Plano Diretor Participativo, regido pela Lei 10.257/2001, que tem como objetivo principal estabelecer a trajetória de expansão dos municípios, engloba a Regularizaçáo Fundiária como instrumento de ordenamento, o que corrobora para a afirmaçáo de que a irregularidade fundiária urbana é um agente do desordenamento da cidade.

A Lei 11.977/2009, em seu art. 46, do Cap. III, aponta que a "regularização fundiária" consiste no conjunto de medidas jurídicas, urbanísticas, ambientais e sociais que visam à regularização de assentamentos irregulares e à titulação de seus ocupantes, de modo a garantir o direito social à moradia, o pleno desenvolvimento das funçóes sociais da propriedade urbana e o direito ao meio ambiente ecologicamente equilibrado. Desse modo, o Ministério das Cidades (2013) enfatiza que a dimensão jurídica se relaciona com a irregularidade dominial, na qual ocorre a inexistência de título que assegure a posse; a urbanística e a ambiental estão associadas aos assentamentos sem licenciamento, em desacordo com a legislação urbana e ambiental; e a social está voltada para o direito à cidade, especialmente nas ocupaçóes de baixa renda.

A modalidade de Regularização Fundiária denominada Interesse Social é o foco deste artigo; portanto, apresenta-se o conceito para esta:

[...] aplicável a assentamentos irregulares ocupados predominantemente por população de baixa renda e que atendam pelo menos um dos seguintes requisitos: estejam ocupados de forma mansa e pacífica há pelo menos 5 anos; estejam localizados em Zona Especial de Interesse Social (ZEIS); ou no caso de áreas públicas, sejam declarados de interesse social para implantação de projetos de regularização fundiária de interesse social. (MINISTÉRIO DAS CIDADES, 2013, p. 19).

Diversos são os instrumentos para regularizar assentamentos. A Figura 1 mostra esses instrumentos e em quais domínios fundiários eles são aplicáveis: 
Figura 1 - Instrumentos de Regularização Fundiária

\begin{tabular}{|c|c|}
\hline DOMíNIO FUNDIÁRIO & INSTRUMENTOS \\
\hline BENS DO ESTADO E DO MUNICÍPIO & $\begin{array}{l}\text { - CONCESSÄO DE USO ESPECIAL PARA FINS DE MORADIA } \\
\text { - AUTORIZAÇÄO URBANÍSTICA DE USO ESPECIAL } \\
\text { - CONCESSÄO DE DIREITO REAL DE USO } \\
\text { - DIREITO DE SUPERFÍCIE } \\
\text { - CESSÄO DE POSSE } \\
\text { - AUTORIZAÇÄO DE USO } \\
\text { - COMPRA E VENDA } \\
\text { - DOAÇÄO } \\
\text { - PERMUTA }\end{array}$ \\
\hline BENS DA UNIÄO & $\begin{array}{l}\text { - CONCESSÄO DE USO ESPECIAL PARA FINS DE MORADIA } \\
\text { - AUTORIZACÄO URBANISTICA DE USO ESPECIAL } \\
\text { - CONCESSÄO DE DIREITO REAL DE USO } \\
\text { - DIREITO DE SUPERFÍCIE } \\
\text { - CESSÄO DE POSSE } \\
\text { - AUTORIZACCĀO DE USO } \\
\text { - COMPRA E VENDA } \\
\text { - DOAÇÄO } \\
\text { - PERMUTA } \\
\text { - CESSÄO DE USO } \\
\text { - AFORAMENTO } \\
\text { - OCUPAÇĀO }\end{array}$ \\
\hline ÁREAS PARTICULARES & $\begin{array}{l}\text { - CONCESSÄO DE DIREITO REAL DE USO } \\
\text { - DIREIIO DE SUPERFÍCIE } \\
\text { - COMPRA E VENDA } \\
\text { - DOACCĀOO } \\
\text { - PERMUTA } \\
\text { - DAÇĀO EM PAGAMENTO } \\
\text { - USUCAPIÄO } \\
\text { - DESAPROPRIAÇÄO }\end{array}$ \\
\hline $\begin{array}{l}\text { BENS DO MUNICÍPIO, ESTADO, UNIÄO E ÁREAS } \\
\text { PARTICULARES }\end{array}$ & $\begin{array}{l}\text { - CONCESSÄO DE DIREITO REAL DE USO } \\
\text { - DIREITO DE SUPERFÍCIE } \\
\text { - COMPRA E VENDA } \\
\text { - DOAÇÄO } \\
\text { - PERMUTA }\end{array}$ \\
\hline
\end{tabular}

Fonte: IJSN (2008, texto digital).

Como o foco deste artigo são áreas de dominialidade pública, apresentam-se instrumentos expostos pelo Ministério das Cidades (2013) para áreas públicas na Figura 2. Ressalta-se que além desses, existe a demarcação urbanística e legitimação de posse, que foram instituídos pela da Lei 11.977/2009. 
Figura 2 - Instrumentos de Regularização Fundiária Urbana de Dominialidade Pública

\begin{tabular}{|c|c|c|c|c|c|}
\hline Finalidade & Instrumento & Aplicaçăo & Titulo & Requisitos & Base Legal \\
\hline \multirow{2}{*}{$\begin{array}{l}\text { Transferância } \\
\text { ou aquisiçảo } \\
\text { de propriedade } \\
\text { (dominio pleno) }\end{array}$} & $\begin{array}{l}\text { Doação } \\
\text { (alienaçă̊ gratuita) }\end{array}$ & Áreas públicas e privadas & $\begin{array}{l}\text { Escritura pública ou } \\
\text { termo administrativo }\end{array}$ & \multirow{2}{*}{$\begin{array}{l}\text { No caso de bens públicos, } \\
\text { prévia avaliaçăo e autoriza̧̧ão } \\
\text { legislativa. Licitaçăo dispensada } \\
\text { no caso de regularização de } \\
\text { interesse social. }\end{array}$} & $\begin{array}{l}\text { Art. } 538 \text { e ss do } \\
\text { Código Civil }\end{array}$ \\
\hline & $\begin{array}{l}\text { Compra e venda } \\
\text { (alienaş̧əo onerosa) }\end{array}$ & Áreas públicas e privadas & $\begin{array}{l}\text { Escritura pública ou } \\
\text { termo administrativo }\end{array}$ & & $\begin{array}{l}\text { Art. } 481 \text { ess do } \\
\text { Código Civil }\end{array}$ \\
\hline \multirow{4}{*}{$\begin{array}{l}\text { Transferància ou } \\
\text { aquisiçăo de dominio } \\
\text { útil (direito real sobre } \\
\text { coisa alheia) }\end{array}$} & \multirow{3}{*}{$\begin{array}{l}\text { CUEM - Concessão de } \\
\text { Uso Especial para fins } \\
\text { de Moradia }\end{array}$} & \multirow[t]{3}{*}{ Áreas públicas } & \multirow[t]{3}{*}{$\begin{array}{l}\text { Termo administrativo } \\
\text { ou sentenşa judicial }\end{array}$} & \multirow{3}{*}{$\begin{array}{l}\text { Posse com intenção de dono, } \\
\text { ininterrupta e sem oposiçăo, } \\
\text { de área urbana de até } 250 \mathrm{~m}^{2} \text {, } \\
\text { anterior a } 30 \text { de junho de } 1996\end{array}$} & $\begin{array}{l}\text { Art. } 49, \mathrm{v}, \mathrm{h} \text { do } \\
\text { Estatuto da Cidade }\end{array}$ \\
\hline & & & & & $\begin{array}{l}\text { Art. } 1225, \mathrm{xI} \text { do } \\
\text { Código Civil }\end{array}$ \\
\hline & & & & & MP $2.220 / 2001$ \\
\hline & $\begin{array}{l}\text { CDRU-Concessão de } \\
\text { Direito Real de Uso }\end{array}$ & Áreas públicas e privadas & $\begin{array}{l}\text { Escritura pública ou } \\
\text { termo administrativo }\end{array}$ & $\begin{array}{l}\text { No caso de bens públicos, } \\
\text { prévia avaliaçăo e autorizaçăo } \\
\text { legislativa. Licitação dispensada } \\
\text { no caso de regularização de } \\
\text { interesse social. }\end{array}$ & $\begin{array}{l}\text { Art. } 79 \text { do Dec. Lei } \\
271 / 1967\end{array}$ \\
\hline \multirow[t]{4}{*}{$\begin{array}{l}\text { Reconhecimento } \\
\text { ou Transferência de } \\
\text { direitos possessórios }\end{array}$} & \multirow[t]{3}{*}{ Legitimaçăo de Posse } & \multirow[t]{3}{*}{$\begin{array}{l}\text { Áreas públicas } \\
\text { ou privadas; }\end{array}$} & \multirow[t]{3}{*}{ Termo administrativo } & $\begin{array}{l}\text { Prévio procedimento de de- } \\
\text { marcação urbanistica em } \\
\text { procedimento de regularização } \\
\text { fundiária de interesse social }\end{array}$ & \multirow[t]{3}{*}{$\begin{array}{l}\text { Art. } 47 \text {, III e } 58 \text { a } \\
60-A \text { da } \\
\text { Lei } 11.977 / 2009\end{array}$} \\
\hline & & & & Posse mansa e pacífica & \\
\hline & & & & $\begin{array}{l}\text { Beneficiário não pode ser con- } \\
\text { cessionário, foreiro ou propri- } \\
\text { etário de outro imóvel urbano } \\
\text { ou rural. }\end{array}$ & \\
\hline & Cessão de Posse & $\begin{array}{l}\text { Áreas em processo de de- } \\
\text { sapropriaç̊̆o com imissð̊o } \\
\text { na posse em favor do ente } \\
\text { expropriante }\end{array}$ & Termo administrativo & $\begin{array}{l}\text { Imissão na posse pelo Poder } \\
\text { Público em processo de desap. } \\
\text { ropriaşăo }\end{array}$ & $\begin{array}{l}\text { Art. } 26,53^{9} \text { a } 59 \text { da } \\
\text { Lei } 6.766 / 1979\end{array}$ \\
\hline
\end{tabular}

Fonte: Ministério das Cidades (2013, texto digital).

Através da Figura 2, percebe-se que diversas são as maneiras de incluir o assentamento no contexto legal, cabe analisar a alternativa mais viável para enquadramento do instrumento e sua respectiva aplicação.

Além das leis e instrumentos já citados, foi aprovada a Medida Provisória No 759 de 22 de dezembro de 2016, que propicia maior fluidez ao processo de regularização fundiária de áreas e imóveis da União, discute a legitimação de posse, e implementa a legitimação fundiária e o direito real de laje.

Frente a tal contexto, afirma-se que a população de baixo poder aquisitivo, ocupante de áreas e imóveis da Uniáo podem requerer diretamente aos cartórios a transferência gratuita da propriedade do imóvel, o que caracteriza a legitimação fundiária. No tocante à legitimação de posse, verifica-se que a Medida Provisória que revoga a Lei 11.977/2009 não trouxe grandes modificaçôes, uma vez que as condiçóes já existentes foram mantidas, dentre elas, a concessão exclusiva pelo poder público e a posterior conversão em propriedade. Já o direito real de laje, auxilia na resolução de uma problemática muito discutida no âmbito da regularização fundiária, que é a coexistência de mais de unidades imobiliárias independentes em mesma área, desde que não sejam encontradas formas de dividir os lotes devido a sobreposição ou solidariedade.

Assim, entende-se que a regularização fundiária é um aspecto intrínseco ao ordenamento urbano, já foram lançados alguns Programas que têm como finalidade reduzir o quadro da irregularidade que assola o Brasil. Dentre eles, pode ser citado o Programa Acesso à Terra Urbanizada, que será o foco de abordagem. 


\section{O PROGRAMA ACESSO À TERRA URBANIZADA EM ATUAÇÁO}

O Programa Acesso à Terra Urbanizada é proveniente de uma parceria entre a Universidade Federal Rural do Semi-Árido do Rio Grande do Norte e o Ministério das Cidades, que tem como principal finalidade promover a Regularizaçáo Fundiária de Interesse Social em áreas urbanas de municípios do Semiárido Nordestino, com meta geral de 3.300 lotes. Teve início em outubro de 2014 e tem como previsão de conclusão junho de 2017.

Quando se fala que a Regularização Fundiária Urbana é o objetivo principal, é porque associado a este alvo o Programa Acesso à Terra Urbanizada tem diversas outras metas: o incentivo à pesquisa e extensão; a formação de profissionais para o mercado de trabalho com caráter multidisciplinar; a conscientização da população sobre a importância da terra legal; a instrumentalizaçáo dos municípios para a continuidade do processo de regularização fundiária e utilização de técnicas e métodos de planejamento urbano; e, dessa forma, a colaboraçáo para o ordenamento territorial.

Pesquisar sobre irregularidade fundiária, características do semiárido e dos municípios de atuaçáo é um elemento presente neste Programa, que dá origem a diversos artigos científicos através dos quais alunos e docentes realizam trocas de experiências com outros pesquisadores, possibilitando a interação e a discussão continuada sobre a problemática urbana. Além dos artigos, entre os anos de 2015 (dois mil e quinze) e 2016 (dois mil e dezesseis) foram elaborados livros e cartilhas, em formato digital e impresso, com temáticas correlacionadas à regularização fundiária.

A extensão, que tem como objetivo socializar os resultados das pesquisas, é concretizada na discussão em eventos científicos e em momentos com a comunidade local dos municípios objeto de intervenção.

Santos Junior (2013) aponta que a Universidade enquanto instituição educativa é ancorada pelos pilares ensino, pesquisa e extensão, sendo estes responsáveis pela formação dos estudantes. Destaca que a extensão universitária está atrelada ao papel social de uma Instituição de Ensino Superior (IES), uma vez que produz conhecimento por meio de experiências em que os sujeitos revezam papel de autores e coautores de autonomia e interdependência, que quando construídas em uma relação dialógica, produzem outros conhecimentos.

Ao citar a formação de recursos humanos especializados de forma multidisciplinar, a execução de tarefas específicas de suas respectivas competências e o conhecimento das demais etapas realizadas pelos outros componentes traduzem esse aspecto, já que ocorre a aquisição experiência em diversos setores. Além disso, os bolsistas participam de eventos e formações que propiciam capacitaçōes de crescimento intelectual, profissional e acadêmico.

A conscientização da população moradora sobre a importância da legalização das áreas é uma etapa crucial para a realização do Programa, pois sem a participação popular, não pode haver o prosseguimento das atividades, uma vez que é opcional regularizar.

São realizados encontros que tratam da regularizaçáo fundiária com os gestores e secretarias dos municípios de intervenção. Esses também auxiliam no desenvolvimento das atividades, dando suporte na coleta de dados e acompanhando a execuçáo das etapas, o que 
permite que adquiram conhecimento para dar continuidade à legalização de áreas de forma individualizada.

A equipe é integrada por pesquisadores, profissionais, de áreas correlatadas, professores mestres e doutores, e bolsistas estudantes dos cursos de Bacharelado em Ciência e Tecnologia, Arquitetura e Urbanismo, Tecnologia da Informação, Engenharia Civil e Direito, que exercem atividades em prol da Regularização Fundiária Urbana de Interesse Social de forma integrada e em diversas equipes: articulação e diagnóstico; jurídico; urbanismo; topografia; social e cadastral; tecnologia da informação; orçamentação. No decorrer da execução, contou com a participação de componentes de todos Câmpus da UFERSA: Angicos/RN, Mossoró/RN, Caraúbas/RN, Pau dos Ferros/RN e, de outras universidades, o que afirma a “multintegração” do Programa.

Para aprimorar a qualidade dos produtos das atividades desenvolvidas, são realizadas periodicamente reunióes de acompanhamento de tarefas e discussão de assuntos pertinentes com os membros da parceria que origina o Programa Acesso à Terra Urbanizada.

Os municípios em atendimento são: São Miguel/RN, Venha-Ver/RN, Portalegre/ RN, Encanto/RN, Luís Gomes/RN, Janduís/RN, Tibau/RN, Assu/RN, Carnaubais/RN e Governador Dix-Sept Rosado/RN. As áreas a serem regularizadas são aquelas apontadas como de dominialidade municipal. Destaca-se que para ser contemplada, é necessário que a área apresente viabilidade técnica e jurídica. A Tabela 1 mostra o quantitativo de lotes por assentamento e município:

Tabela 1 - Quantidade de lotes por assentamento e município

\begin{tabular}{|c|c|c|c|}
\hline Município & Assentamentos & Quantidade de Lotes & Total \\
\hline \multirow{2}{*}{ Encanto } & Antônio Cajazeiras & 77 & \multirow{2}{*}{285} \\
\hline & São Luiz & 208 & \\
\hline \multirow{2}{*}{ São Miguel } & Nossa Senhora de Guadalupe & 152 & \multirow{2}{*}{287} \\
\hline & Tôta Barbosa & 135 & \\
\hline \multirow{4}{*}{ Venha-Ver } & Frei Damião & 61 & \multirow{4}{*}{176} \\
\hline & $\begin{array}{c}\text { Nossa Senhora do Perpétuo } \\
\text { Socorro } \\
\end{array}$ & 46 & \\
\hline & Santo Expedito & 50 & \\
\hline & Centro & 19 & \\
\hline \multirow{2}{*}{$\begin{array}{l}\text { Governador Dix-Sept } \\
\text { Rosado }\end{array}$} & Sítio Cigana & 162 & \multirow{2}{*}{277} \\
\hline & Francisco Liberato & 115 & \\
\hline Luís Gomes & São José & 141 & 141 \\
\hline Carnaubais & $\begin{array}{l}\text { João Teixeira Filho e Valdemar } \\
\text { Campielo }\end{array}$ & 278 & 278 \\
\hline \multirow{2}{*}{ Janduís } & Sáo Bento & 82 & \multirow{2}{*}{166} \\
\hline & Lourival Gurgel & 84 & \\
\hline
\end{tabular}




\begin{tabular}{c|c|c|c}
\hline Município & Assentamentos & Quantidade de Lotes & Total \\
\hline Portalegre & Carrapicho & 83 & 83 \\
\hline Assú & Parati & 1.406 & 1.406 \\
\hline \multirow{2}{*}{ Tibau } & Vila dos Cajueiros & 93 & \multirow{2}{*}{122} \\
\cline { 2 - 3 } & Valdecir Ferreira & 29 & \multirow{2}{*}{$\mathbf{3 . 2 2 1}$} \\
\hline TOTAL & $\mathbf{1 8}$ & $\mathbf{3 . 2 2 1}$ & \\
\hline
\end{tabular}

Fonte: Acervo de Dados do Programa Acesso à Terra Urbanizada, 2016.

O quantitativo citado na Tabela 1 apresenta todos os lotes dos assentamentos, residenciais, vazios, em construção, institucionais, comerciais e mistos. Além desses assentamentos, havia uma previsão de mais 183 lotes, correspondentes aos assentamentos Bartolomeu (Venha-Ver) - 19 lotes; Mirante (Luís Gomes) - 59 lotes - e São José (Portalegre) - 105 lotes. Porém, esses assentamentos foram descartados devido à inviabilidade jurídicofundiária para efetivação da Regularização Fundiária.

Após a escolha da área são realizadas as seguintes atividades: caracterização de áreas, trabalho social, cartografia básica, regularização da base imobiliária, levantamento cadastral, levantamento social, elaboração do projeto de regularização fundiária, parcelamento do solo, registro e titulação.

$\mathrm{Na}$ caracterização de áreas, executam-se: busca cartorária para verificação da situação jurídico-fundiária da base imobiliária; visitas aos assentamentos para identificação da infraestrutura básica existente; entrevista com os moradores mais antigos para conhecimento do histórico, tempo e forma de ocupação. Essa etapa é fundamental para que as demais possam ser iniciadas, pois é através dela que se verifica a viabilidade de instauração da Regularização Fundiária de Interesse Social.

O trabalho social consiste nas ações de sensibilização, mobilização, informação, capacitação e envolvimento da população moradora para participação no processo de regularização fundiária. As atividades referentes ao trabalho social do Programa Acesso à Terra Urbanizada dividem-se em:

1) Identificação das Lideranças Locais e Organizações Comunitárias: realização de reunião com integrantes de secretarias municipais que possam identificar as lideranças comunitárias (assistência social, tributação, administração, por exemplo) e consequente contato prévio para agendamento de reuniáo sobre Regularização Fundiária;

2) Reunião com o Conselho de Regularização Fundiária do Município (quando existe ou está em fase de constituição) - Nesta fase, a equipe de Articulação e Diagnóstico apresenta levantamento preliminar das áreas em estudo para a realização de Regularização Fundiária de Interesse Social, expõe informaçóes relevantes do Programa Acesso à Terra Urbanizada, mostra a importância do engajamento do Conselho no desenrolar de suas açóes e participa do processo de constituição do conselho em caso de está em fase de consolidação; 
3) Reunião com as lideranças comunitárias - Neste momento é realizada a explanação de conceitos inerentes à Regularização Fundiária e a explicação do Programa Acesso à Terra Urbanizada, elencando-se aspectos como: o que é o Programa, qual o seu objetivo, quais os critérios para ser beneficiado e documentos necessários para que o título de posse seja emitido. Além disso, executam-se oficinas, que utilizam estudos de caso que possibilitam analisar o grau de entendimento do Programa e da importância da Regularização Fundiária para a população;

4) Participação em rádios comunitárias - Bolsistas da Equipe Social e Cadastral expóem o Projeto, a relevância da Regularização Fundiária, os principais agentes envolvidos neste processo, e convida a população dos bairros em estudo para verificação de viabilidade de Regularização Fundiária de Interesse Social que a rádio atinge (geralmente a todos os bairros pré-selecionados de um município) para a reunião de apresentação do Programa;

5) Entrega de convites à população moradora - A Equipe Social e Cadastral envia o arquivo digital com convites da assembleia de entrada com a população moradora e o município se responsabiliza pela impressão e entrega a cada família;

6) Reunião com os moradores dos bairros a serem beneficiados - Aqui, expóe-se o Projeto, sua finalidade, as áreas em estudo, qual o motivo da pré-seleção desses conjuntos ou bairros, a definição de Regularização Fundiária e suas especificações, os requisitos para ser beneficiado com a escritura pública e são esclarecidas as dúvidas que os moradores têm a respeito da execução da Regularização Fundiária pelo Programa.

Vale ressaltar que não necessariamente todas as etapas descritas anteriormente são aplicadas para todos os municípios, visto que alguns não dispóem de conselhos específicos para regularização fundiária ou a metodologia de disseminação de informaçóes varia de acordo com a cidade. As Figuras 3 e 4 mostram algumas açóes sensibilização e mobilização.

Figura 3 - Reunião com a Comunidade de Assu/RN

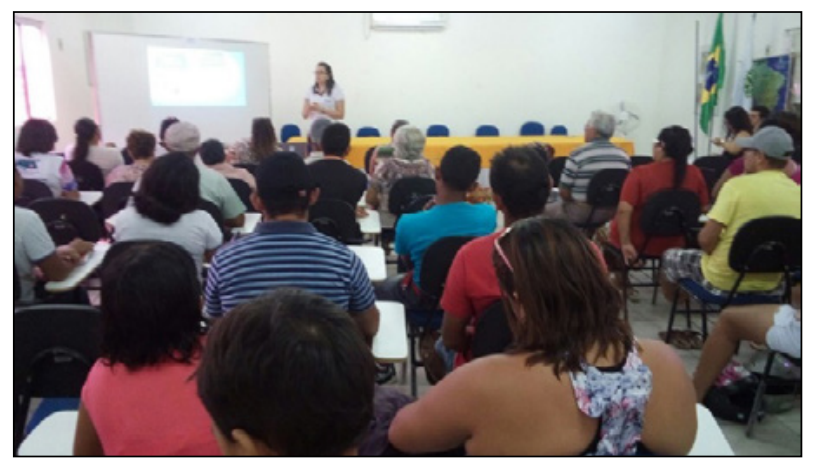

Fonte: Acervo de Dados do Programa Acesso à Terra Urbanizada, 2016. 
Figura 4 - Reunião com líderes comunitários de Venha-Ver/RN

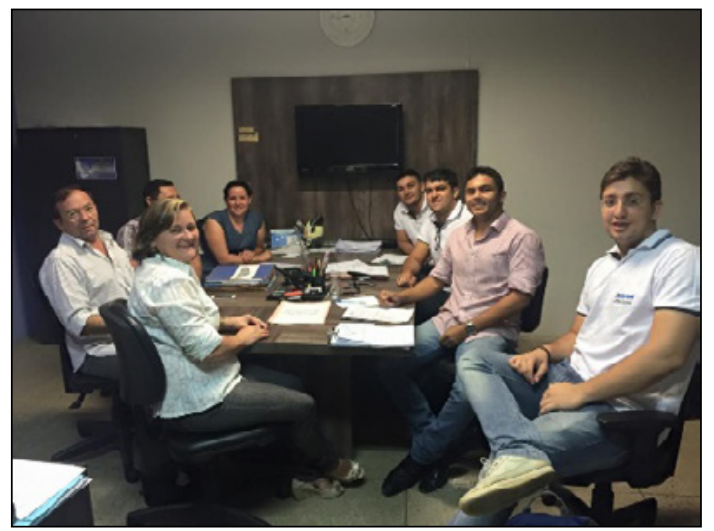

Fonte: Acervo de Dados do Programa Acesso à Terra Urbanizada, 2016.

Na cartografia básica é realizado o levantamento planialtimétrico cadastral, que apresenta as medidas e ângulos da gleba, além da locação de detalhes visíveis de interesse. As fases para elaboração da cartografia básica pelo supracitado Programa são mostradas na Figura 5.

Figura 5 - Fluxograma de etapas para execução da cartografia básica através do Programa Acesso à Terra Urbanizada

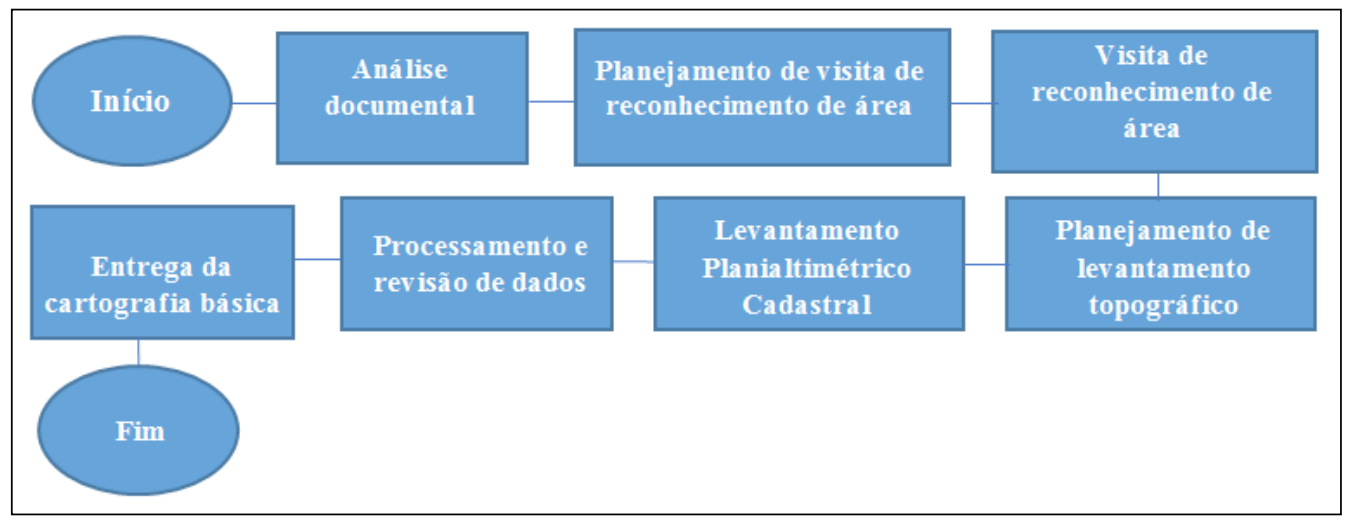

Fonte: Elaborado pelos autores, 2017.

$\mathrm{Na}$ análise documental, as matrículas e demais dados concernentes às áreas a serem levantadas são examinadas com a finalidade de tornar a equipe de cartografia básica inteirada das dimensóes registradas e configuraçóes dos assentamentos.

Já no planejamento de visita de reconhecimento de área, dimensiona-se a equipe que irá a campo para verificar a gleba junto a um representante municipal; traça-se a poligonal básica das áreas em imagem aérea e prepara-se documentação de apoio, tais como croquis e cópias de matrículas; agenda-se a visita com o agente do município que acompanhará a equipe aos assentamentos em análise. 
$\mathrm{Na}$ visita de reconhecimento de área, delimita-se o perímetro da gleba e obtêm-se as coordenadas geodésicas correspondentes aos assentamentos objeto de estudo para fins de regularização fundiária de interesse social.

Mediante apropriaçáo de todas as informaçóes referentes às etapas descritas anteriormente, é feito planejamento para realização do levantamento planialtimétrico cadastral, no qual são especificados os integrantes da equipe que trabalharão em cada área; estimado o tempo a ser utilizado para a execuçáo das atividades e programada data de ida a campo.

Depois de realizadas todas as fases que já foram especificadas, a equipe de topografia se direciona a campo para realizar o levantamento planialtimétrico cadastral com o auxílio dos equipamentos necessários, que dará origem à cartografia básica dos assentamentos.

Dispondo dos dados do levantamento, é feito o seu processamento com softwares específicos e realizada verificação das informaçóes para checar a necessidade de voltar às áreas. A Figura 6 exemplifica um levantamento planialtimétrico:

Figura 6 - Levantamento planialtimétrico assentamento Carrapicho - Portalegre/RN

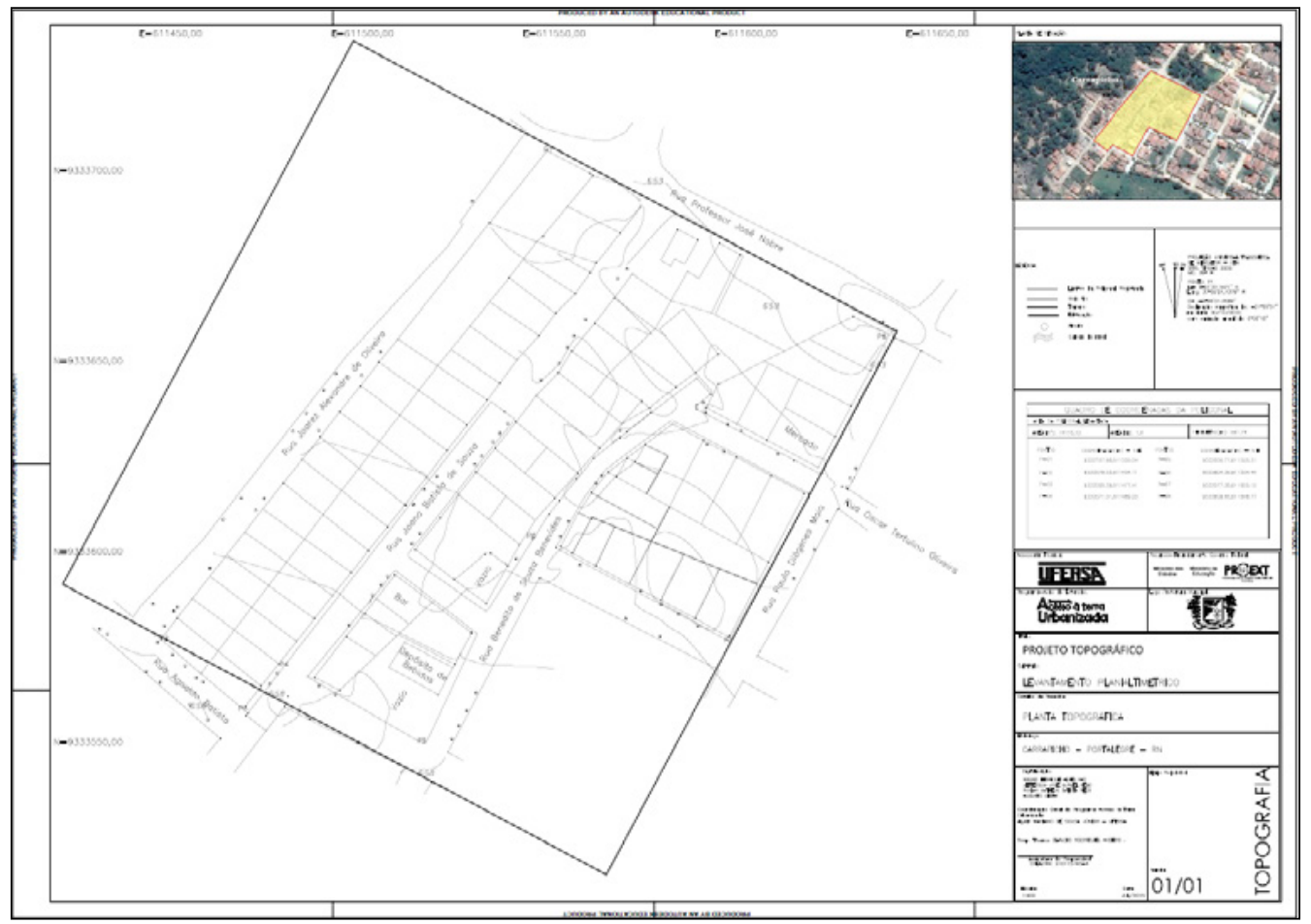

Fonte: Acervo de Dados do Programa Acesso à Terra Urbanizada, 2016.

Para a Regularização da Base Imobiliária dos assentamentos a serem regularizadas, realiza-se a identificação das áreas registradas e as áreas existentes, executando-se a sobreposição das duas realidades para verificação de coerência ou divergência para a efetivação de procedimentos posteriores, como retificação de matrícula, por exemplo. 
O levantamento cadastral consiste em elaborar o cadastro físico dos imóveis compreendendo a identificação, a codificação e a delimitação dos lotes e dos domicílios existentes na área, a caracterização do uso (residencial, misto, comercial, institucional, de prestação de serviços), as condições gerais de habitabilidade das edificações, entre outros. $\mathrm{O}$ Quadro 1 expressa um exemplo de cadastro físico realizado no município de São Miguel/ RN.

Quadro 1 - Cadastro Físico São Miguel/RN, assentamento Nossa Senhora de Guadalupe, Quadra 02, lote 20

\begin{tabular}{|l|}
\hline \multicolumn{1}{|c|}{ CADASTRO FÍSICO } \\
Identificação: Quadra 2 - Lote 20 \\
Caracterizaçáo do Uso: Residencial \\
Condiçóes de Moradia: Adequado \\
Área do Lote $\left(\mathrm{m}^{2}\right):$ : 60.71 \\
\hline Delimitaçáo dos Lotes: \\
Frente: $4.32 \mathrm{~m}$ (Rua Projetada) \\
Direita: $15.95 \mathrm{~m}$ (Lote 30$)$ \\
Fundo: $3.44 \mathrm{~m}$ (Lote 150$)$ \\
Esquerda: $15.45 \mathrm{~m}$ (Lote 10$)$ \\
\hline
\end{tabular}

Fonte: Acervo de Dados do Programa Acesso à Terra Urbanizada, 2016.

Durante as visitas aos cartórios, percebeu-se que muitos dos confrontantes das residências geralmente não possuem registro, o que dificulta a atualização cadastral quando se realiza vendas ou trocas. Desse modo, utilizou-se nomes de ruas e numeração de lotes para tal especificação.

No que se refere ao levantamento social, são elaborados cadastros socioeconômicos dos moradores com respectiva coleta de documentos correspondentes a cada classificação do imóvel (residencial, institucional, comercial, misto). Para domicílio são verificados os dados: endereço, composição familiar, tempo de ocupação, características internas da construção (fornecimento de energia; instalação elétrica; piso; forro; número de cômodos, quartos e banheiros; utilização do sanitário; localização do sanitário), saneamento básico e meio ambiente (sistema de esgoto sanitário; destinação do lixo; tipo de abastecimento de água), registro de imóvel; já para atividades comerciais: razão social, inscrição estadual, Cadastro Nacional de Pessoa Jurídica (CNPJ), inscrição municipal, caracterização do imóvel (restaurante, motel, pousada, hotel, casa noturna, oficina, locadora de veículos, posto de combustível, banco, agência de turismo, ponto de venda, número de funcionários, número de pessoas da família envolvidas, área construída, receita mensal estimada); e para instituições: existência ou não de estatuto social registrado, Cadastro Nacional das Entidades de Assistência Social (CNEAS), utilidade pública municipal ou estadual e respectivas leis, atividades desenvolvidas (assistenciais, culturais, esportivas, recreativas, profissionalizantes, reuniôes, ensino regular, oficinas, cultos religiosos), público alvo, formas de manutenção 
da instituição, características internas da construção, saneamento básico e meio ambiente (mesmos dados do formulário domiciliar).

O projeto de regularização fundiária foi organizado compreendendo no mínimo as áreas ou lotes a serem regularizados e, se houver necessidade, as edificaçóes que serão relocadas; as vias de circulação existentes ou projetadas e, se possível, as outras áreas destinadas a uso público; análise da área para verificação ambiental e urbanística e apontamento de soluçóes, caso necessário. A Figura 7 corresponde à planta urbanística do assentamento São José Luís Gomes/RN, que servirá para o parcelamento do solo.

Figura 7 - Planta de Parcelamento do Solo do São José - Luís Gomes/RN

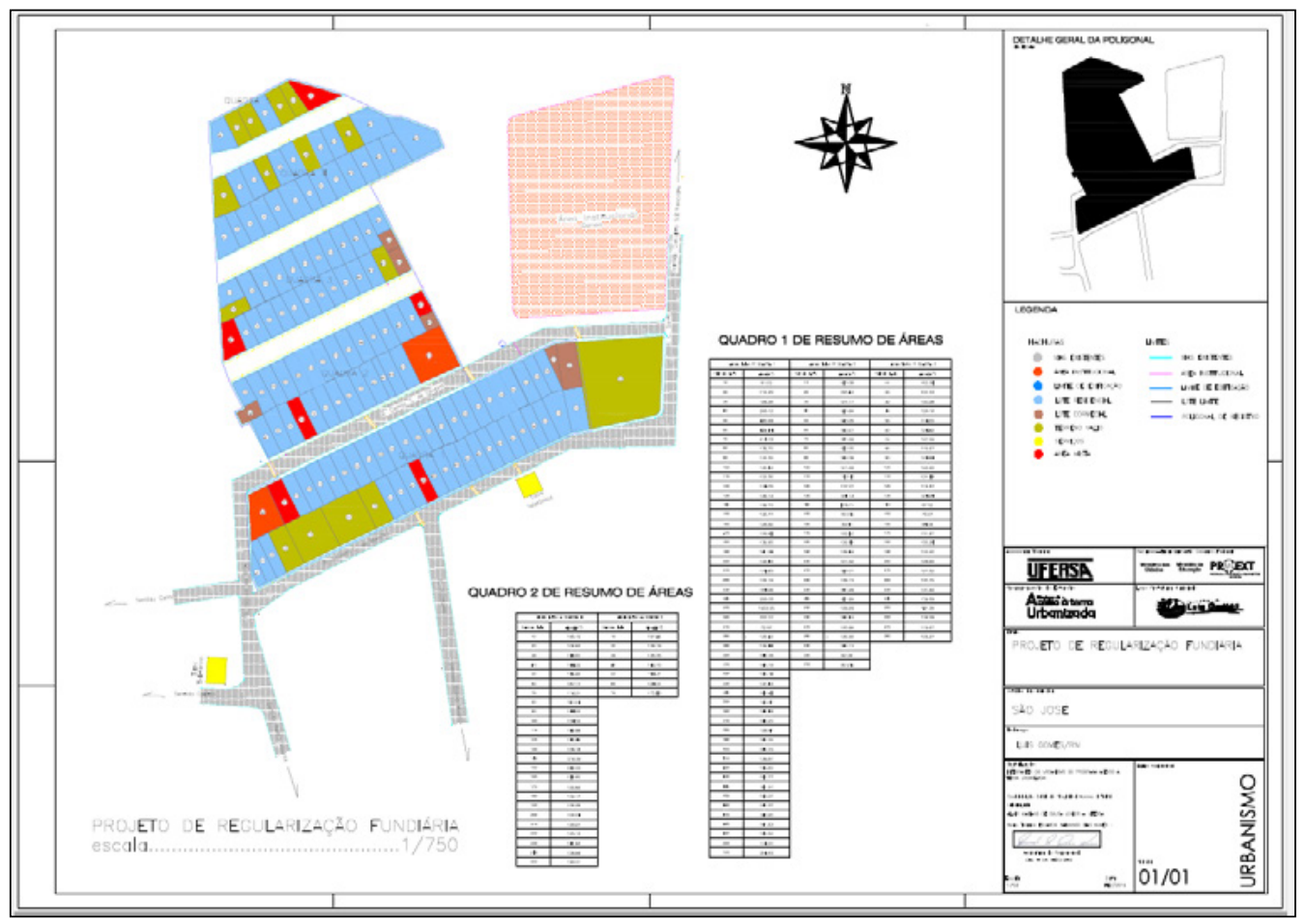

Fonte: Acervo de Dados do Programa Acesso à Terra Urbanizada, 2016.

$\mathrm{Na}$ plotagem da planta urbanística são apresentadas as áreas de cada lote e hachuras diferenciadas de acordo com a classificação do lote. A Figura 8 representa a legenda usada para este assentamento. 
Figura 8 - Legenda para planta de parcelamento

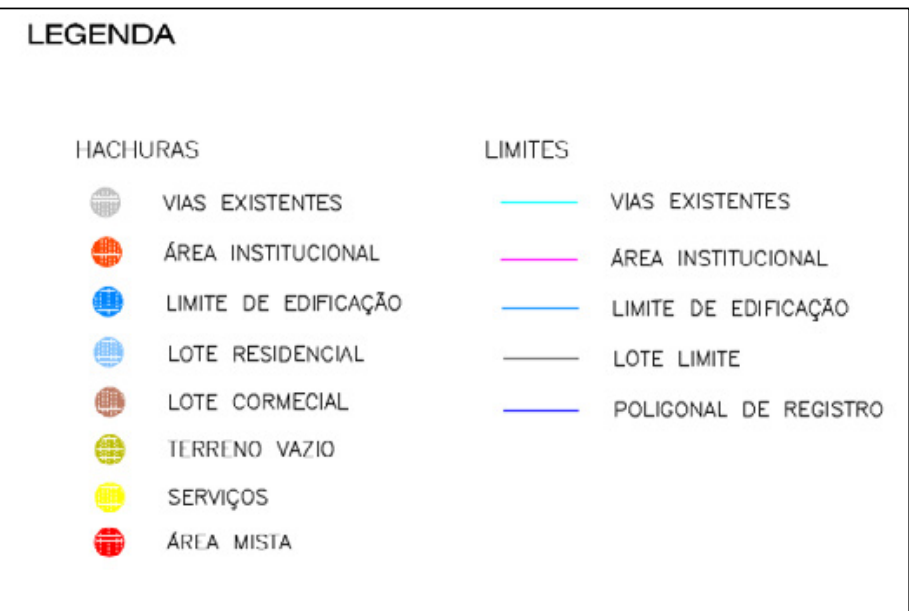

Fonte: Acervo de Dados do Programa Acesso à Terra Urbanizada, 2016.

No projeto de Regularização Fundiária, apresenta-se o quantitativo de lotes por categoria, conforme podemos visualizar na Tabela 2.

Tabela 2 - Classificação dos lotes do assentamento São José - Luís Gomes/RN

\begin{tabular}{cccc}
\hline \multicolumn{4}{c}{ NATUREZA DO LOTEAMENTO } \\
\hline LOTES & No & ÁREA $(\mathrm{m} 2)$ & $\%$ \\
\hline Lotes Residenciais & 119 & $17.306,30$ & 81,26 \\
Lotes Comerciais & 6 & 591,81 & 2,78 \\
Lotes Vazios & 14 & $2.615,41$ & 12,28 \\
Igreja & 2 & 783,54 & 3,68 \\
\hline TOTAL & 141 & $21.298,14$ & 100 \\
\hline
\end{tabular}

Fonte: Acervo de Dados do Programa Acesso à Terra Urbanizada, 2016.

Conforme o relatório de diagnóstico inerente ao Projeto de Regularização Fundiária, a gleba correspondente à Tabela 2 não apresenta casos graves de acidentes de terreno, porém algumas vias possuem elevadas erosões, que prejudicam o trânsito; não há corpos d'água; devido a algumas inclinaçōes, as vias acabam se tornando linhas de drenagem, o que causa erosôes no terreno; a área com maior declividade está situada próximo às quadras 4 e 5; não há rodovia, ferrovia ou adutoras na gleba e a transmissão de energia é dada por rede de baixa tensão; não há nenhum caso de lote em condiçôes extremas de precariedade que incida na necessidade de demolição.

Sobre as condiçóes infraestruturais, o abastecimento de água se faz por meio de caminhóes-tanque; não existe sistema de esgoto e drenagem; portanto, os resíduos são destinados a fossas sépticas, e em alguns casos o despejo de esgoto é a céu aberto; a 
distribuição de energia elétrica é realizada pela concessionária do Estado; não há qualquer guia ou sarjeta nessa gleba; há estradas pavimentadas e não pavimentadas; ocorre coleta de lixo.

Com a conclusão desses procedimentos, a planta urbanística é protocolada no município. Após, são emitidos os títulos da modalidade escolhida (CDRU, CUEM, Doação, por exemplo), coletadas as assinaturas dos moradores aptos e, posteriormente, do gestor municipal para serem encaminhados ao cartório para parcelamento e abertura de matrículas individualizadas.

As Figuras 9 e 10 mostram a assinatura de títulos pela comunidade do assentamento Parati, localizado em Assu/RN, que como mostra a Tabela 1, é o responsável pelo maior quantitativo de lotes do Programa Acesso à Terra Urbanizada.

Figura 9 - Assinatura de Títulos em Assu/RN

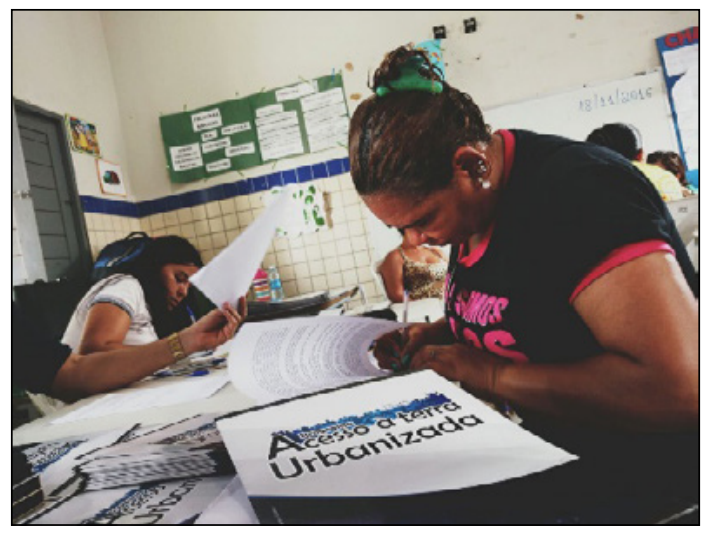

Fonte: Acervo de Dados do Programa Acesso à Terra Urbanizada, 2016.

Figura 10 - Assinatura de Títulos em Assu/RN

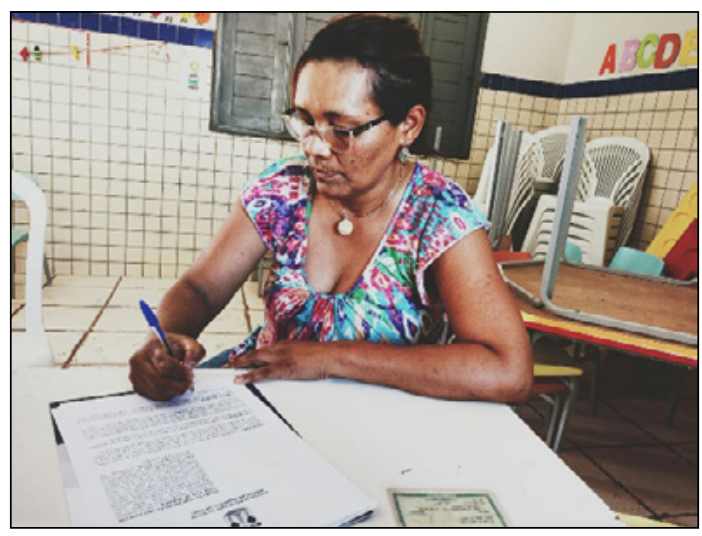

Fonte: Acervo de Dados do Programa Acesso à Terra Urbanizada, 2016. 
A modalidade de título escolhido para o Parati foi a Concessão de Uso Especial para Fins de Moradia (CUEM), uma vez que o assentamento teve sua matrícula originada 1996, antes do dia 30 de junho do referido ano, condição para aplicaçáo deste instrumento.

$\mathrm{O}$ último procedimento é a entrega de títulos aos moradores, que terão o direito à moradia garantido legalmente. As Figuras 11 e 12 referem-se à cerimônia de entrega de declaraçáo de aptidáo para recebimento de título e informe de matrícula correspondente a cada lote.

Figura 11 - Evento de titulação em Assu/RN

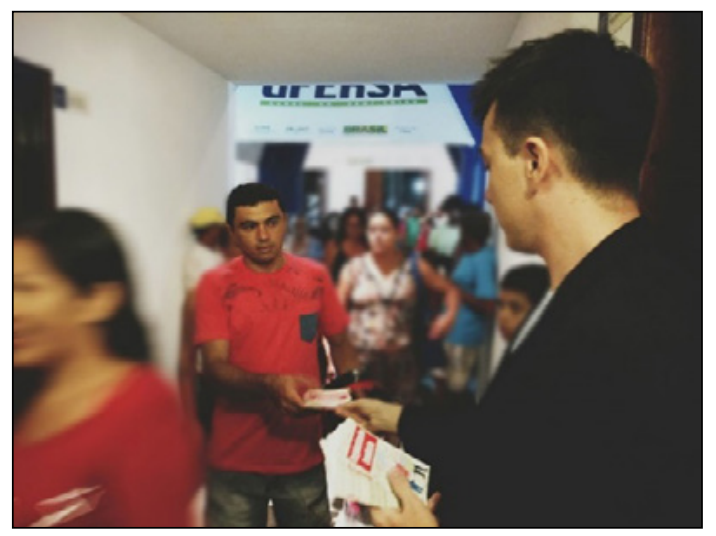

Fonte: Acervo de Dados do Programa Acesso à Terra Urbanizada, 2016.

Figura 12 - Evento de titulação em Assu/RN

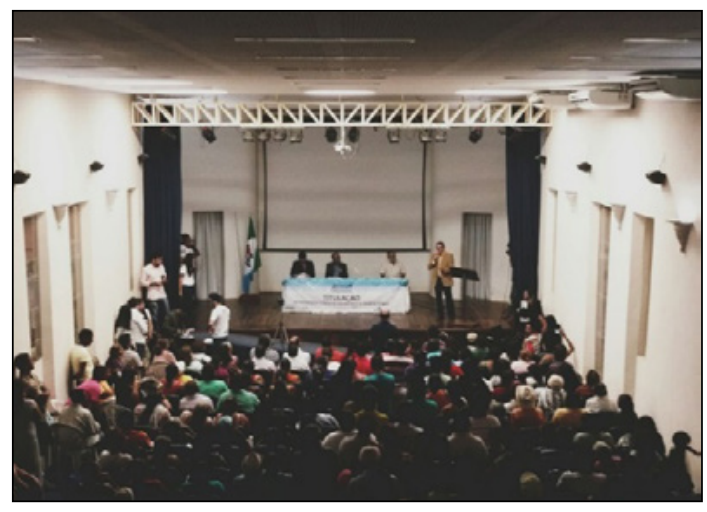

Fonte: Acervo de Dados do Programa Acesso à Terra Urbanizada, 2016.

Gonçalves (2009) aponta que a legalizaçáo da moradia garante recursos indispensáveis para o enfrentamento de diversos conflitos de ordem fundiária e imobiliária, além de propor iniciativas públicas de ordem urbanística, suprimindo possíveis situações de risco, e ampliando a efetividade da gestáo do espaço. 
Neste contexto, destaca-se que as etapas de Regularização Fundiária de Interesse Social Urbana como: caracterização de áreas, cartografia básica, levantamento cadastral, levantamento social, elaboração do projeto de regularização fundiária, parcelamento do solo podem ser tidas como mecanismos de planejamento territorial, uma vez que apresentam as características específicas de cada área o que influi na política pública que mais se adeque para este assentamento.

\section{CONSIDERAÇÓES FINAIS}

A regularizaçáo fundiária é um elemento essencial do ordenamento urbano, pois através de sua execução a inclusão dos assentamentos irregulares no contexto legal é efetivada e, consequentemente, as melhorias infraestruturais são potencializadas, ampliando o bemestar da população.

O Programa Acesso à Terra Urbanizada é uma ação que colabora ativamente para redução do cenário irregular que assola o Brasil, especialmente para as pessoas que não têm condiçóes financeiras de legalizar seu lote devido à onerosidade do processo de regularização, pois trabalha com Regularização Fundiária de Interesse Social.

Atividades de Regularização Fundiária de Interesse Social Urbana desenvolvidas após o período de investigação para este trabalho estão propícias a adotarem os instrumentos da Medida Provisória 759/2016. Entretanto, esse procedimento poderá impactar na qualidade do produto final, visto que na metodologia instituída por esta Medida Provisória algumas etapas técnicas foram suprimidas com o objetivo de simplificar e reduzir os custos do processo.

As contribuições do Programa Acesso à Terra Urbanizada superam a atribuição de um título que assegure a posse de moradias para comunidades, pois suas atividades multidisciplinares envolvem discentes e docentes, incentivando a pesquisa e extensão, além de contemplarem estudos que podem ser julgados como subsídios ao ordenamento territorial, uma vez que descrevem com detalhes as características de áreas em foco, possibilitando a adoção de medidas de melhoria pelo poder público.

Portanto, as etapas para a regularizaçáo fundiária desenvolvidas por meio do referido Programa são aportes para o planejamento urbano, queé fundamental para o desenvolvimento territorial, uma vez que através delas é possível traçar o perfil das localidades estudadas e destinar açôes específicas de acordo com as problemáticas existentes neste território.

\section{REFERÊNCIAS}

BRASIL. Lei 10.257, de 10 de julho de 2001. Estatuto da Cidade. Disponível em: < http://www.planalto.gov.br/ccivil_03/leis/LEIS_2001/L10257.htm>. Acesso em: 28 fev. 2017.

BRASIL. Lei 11.977, de 07 de julho de 2009. Dispóe sobre o Programa Minha Casa, Minha Vida - PMCMV e a regularização fundiária de assentamentos localizados em áreas 
urbanas... Disponível em: < http://www.planalto.gov.br/ccivil_03/_ato2007-2010/2009/ lei/l11977.htm>. Acesso em: 28 fev. 2017.

BRASIL. Medida Provisória 759, de 22 de dezembro de 2016. Dispóe sobre a regularização fundiária rural e urbana... Disponível em: <http://www.planalto.gov.br/ ccivil_03/_ato2015-2018/2016/Mpv/mpv759.htm>. Acesso em: 28 abr. 2017.

BRASIL. Ministério das Cidades. Regularizaçáo Fundiária Urbana no Brasil. Brasília, 2009. Disponível em: <http://www.capacidades.gov.br/biblioteca/detalhar/id/172/titulo/ regularizacao--fundiaria-urbana--no-brasil->. Acesso em: 28 fev. 2017.

BRASIL. Ministério das Cidades. Secretaria Nacional de Acessibilidade e Programas Urbanos e Secretaria Nacional de Habitação. Regularizaçáo Fundiária Urbana: Como aplicar a Lei Federal 11.977/2009. Brasília, 2013. Disponível em: <http://www.sjc.sp.gov. $\mathrm{br} / \mathrm{media} / 621520 /$ regularizacao_fundiaria_cartilha_da_lei_federal.pdf $>$. Acesso em: 28 fev. 2017.

BRASIL. Ministério das Cidades. Estatuto da Cidade e Regularizaçáo Fundiária. Brasília, 2014. Disponível em: <http://www.planejamento.gov.br/assuntos/patrimonioda-uniao/programa-de-modernizacao/linha-do-tempo/arquivos-e-publicacoes/estatuto-dacidade-e-regularizacao-fundiaria.pdf>. Acesso em: 28 fev. 2017.

FERNANDES, Edésio. Regularizaçáo de Assentamentos Informais na América Latina. Cambrige: Lincoln Institute of Land Policy, 2011.

GONÇALVES, Rafael Soares. Repensar a Regularização Fundiária como Política de Integração Socioespacial. Revista Estudos Avançados, São Paulo, v. 23, n. 66, p.237-250, 2009. Disponível em: <http://www.scielo.br/pdf/ea/v23n66/a17v2366.pdf>. Acesso em: 29 abr. 2017.

INSTITUTO JONES DOS SANTOS NEVES - IJSN. Habitaçáo e regularizaçáo fundiária: Instrumentos para repasse. Vitória, 2008. Disponível em: <http://www.ijsn. es.gov.br/ConteudoDigital/20120822_habitacaoeregularizacao_fundiaria2008.pdf>. Acesso em: 28 fev. 2017.

MARICATO, Ermínia. Metrópole, legislação e desigualdade. Revista Estudos Avançados, São Paulo, v. 17, n. 48, p.151-166, ago. 2003. Disponível em: <http://www. scielo.br/pdf/ea/v17n48/v17n48a13.pdf >. Acesso em: 27 fev. 2017.

\section{SANTOS JÚNIOR, Alcides Leão. A Extensáo Universitária e os Entre-Laços dos}

Sabores. 2013. 265 f. Tese (Doutorado em Educação) - Universidade Federal da Bahia, Salvador, 28 fev. 2013. Disponível em: < https://repositorio.ufba.br/ri/bitstream/ ri/17554/1/A\%20EXTENS\%C3\%83O\%20UNIVERSIT\%C3\%81RIA\%20E\%20 OS\%20ENTRE-LA\%C3\%87OS\%20DOS\%20SABERES.pdf>. Acesso em: 29 abr. 2017. 